Chapter 12

\title{
Benign Hepatic Neoplasms
}

\author{
Ronald S. Chamberlain and Kim Oelhafen
}

Additional information is available at the end of the chapter

http://dx.doi.org/10.5772/53848

\section{Introduction}

Historically benign liver tumors were encountered incidentally during laparotomy or more recently during laparoscopy at which time definitive histological diagnosis can be established. However, with the utilization of advanced imaging modalities hepatic neoplasms have been increasingly identified, with a prevalence rate of up to $50 \%$ reported among the general population [1]. Among these incidental lesions, $83 \%$ were characterized as benign neoplasms, as outlined in Table 1 [1-3]. Benign hepatic neoplasms represent a diverse group of tumors that develop from either epithelial or mesenchymal cell lines (Table 2), and while the frequency of such lesions is not well documented, more than $50 \%$ are classified as hemangiomas [1]. Focal nodular hyperplasia $(\mathrm{FNH})$ and hepatic adenomas represent the next most frequently diagnosed benign tumors. A variety of additional exceedingly rare benign lesions have also been described most of which are sufficiently infrequent enough to be classified as "fascinomas" [1].

\begin{tabular}{cc}
\hline Neoplasm & Relative frequency \\
\hline Hemangioma & $52 \%$ \\
\hline Focal nodular hyperplasia & $11 \%$ \\
\hline Metastatic tumor $\left(\mathrm{T}_{\mathrm{x}} \mathrm{N}_{\mathrm{x}} \mathrm{M} 1\right)$ & $11 \%$ \\
\hline Hepatocellular adenoma & $8 \%$ \\
\hline Focal fatty infiltration & $8 \%$ \\
\hline Hepatocellular carcinoma & $6 \%$ \\
\hline Extrahepatic process (eg., & $3 \%$ \\
\hline abscess, adrenal tumor) & $1 \%$ \\
\hline Other benign hepatic process
\end{tabular}

Table 1. Diagnostic frequency of incidentally identified solid liver neoplasms $s^{1,2,9}$ 


\begin{tabular}{|c|c|}
\hline Cell of origin & Tumors \\
\hline \multicolumn{2}{|l|}{ Epithelial } \\
\hline \multirow[t]{3}{*}{ Hepatocellular } & Focal nodular hyperplasia (FNH) \\
\hline & Hepatocellular adenoma (HA) \\
\hline & Regenerative nodule \\
\hline \multirow[t]{2}{*}{ Cholangiocellular } & Biliary adenoma \\
\hline & Biliary cystadenoma \\
\hline Other & Epitheliod leiomyoma \\
\hline \multicolumn{2}{|l|}{ Mesenchymal } \\
\hline \multirow[t]{6}{*}{ Endothelial } & Hemangioma \\
\hline & Cavernous \\
\hline & Capillary \\
\hline & Hemangioendothelioma \\
\hline & Adult \\
\hline & Infantile \\
\hline \multirow[t]{3}{*}{ Mesothelial } & Solitary fibrous tumor \\
\hline & Benign mesothelioma \\
\hline & Fibroma \\
\hline \multirow[t]{3}{*}{ Adipocyte } & Lipoma \\
\hline & Myelolipoma \\
\hline & Angiomyelipoma \\
\hline \multicolumn{2}{|l|}{ Miscellaneous } \\
\hline Tumors & Biliary hamartoma \\
\hline
\end{tabular}

Table 2. Benign solid liver neoplasms $s^{1,9}$

Most benign tumors are asymptomatic which makes standardizing the work-up difficult. The evaluation of incidental solid hepatic tumors should be individualized based upon the patient's age, sex, past medical history, medications, and associated clinical signs. Although physical examination of the abdomen is typically unremarkable it may rarely reveal localized tenderness and/or a palpable mass. Liver function tests are indicated though are seldom abnormal in asymptomatic patients. Additional laboratory testing such as alpha-fetoprotein (AFP), carcinoembryonic antigen (CEA), carbohydrate antigen (CA) 19-9 and, lactate dehydrogenases may also be ordered depending on the clinical scenario.

Substantial advancements and the widespread availability and use of modern imaging modalities to diagnose and treat abdominal pain, has led to a marked increase in the identification of benign liver tumors. A full discussion of the advantages and disadvantages of 
individual imaging techniques is beyond the scope of this chapter but is outlined in Table 3. Briefly, B-mode ultrasonography (US) can effectively differentiate cystic and solid neoplasms and is usually the initial study of choice [4,5]. Contrast-enhanced computed tomography (CT) provides greater sensitivity than US for determination of lesion number, size, and location [5, 6]. Magnetic resonance imaging (MRI) represents the most sensitive and specific study to discriminate between various benign liver lesions, particularly when contrast agents are used [5-7]. Finally, fluorodeoxyglucose positron emission tomography $\left({ }^{18}\right.$ FDG-PET) can aid in the differentiation of benign versus malignant tumors based on the metabolic activity of the lesion [8]. Although modern imaging techniques can precisely diagnose the vast majority of incidental benign tumors, laparoscopic or open biopsy is necessary to exclude malignancy when precise diagnosis remains elusive.

\begin{tabular}{|c|c|c|c|c|c|}
\hline $\begin{array}{l}\text { Tumor } \\
\text { Hemangioma }\end{array}$ & $\begin{array}{l}\text { US } \\
\text { Hyperechoic } \\
\text { Well-demarcated } \\
\text { Increased vascular flow } \\
\text { Central venous pooling }\end{array}$ & $\begin{array}{l}\text { CT } \\
\text { Highly sensitive } \\
\text { Non-contrast: Isodense } \\
\text { Contrast: Hypoense } \\
\text { Irregular peripheral enhancement } \\
\text { with delayed central filling }\end{array}$ & $\begin{array}{l}\text { MRI } \\
\text { Highly sensitive } \\
\text { Isodense on T1 } \\
\text { Hyperdense on T2 } \\
\text { Gadolinium enhanced } \\
\text { scan shows similar } \\
\text { findings to contrast CT }\end{array}$ & $\begin{array}{l}\text { Tc } 99 \text { RBC scan } \\
\text { Blood pooling of } \\
\text { radionucleotide }\end{array}$ & $\begin{array}{l}\text { Tc } 99 \text { SC scan } \\
\text { Not indicated }\end{array}$ \\
\hline $\begin{array}{l}\text { Focal Nodular } \\
\text { Hyperplasia } \\
\text { (FNH) }\end{array}$ & $\begin{array}{l}\text { Non-specific } \\
\text { Hyperechoic }\end{array}$ & $\begin{array}{l}\text { Highly specific } \\
\text { Non-contrast: isodense } \\
\text { Contrast: isodense } \\
\text { and well-demarcated } \\
\text { with central scar }\end{array}$ & $\begin{array}{l}\text { Highly specific } \\
\text { Isodense of T1 \& T2 } \\
\text { Early hyperdense } \\
\text { after gadolinium }\end{array}$ & Not indicated & $\begin{array}{l}\text { Takes up Tc99 } \\
\text { Tc99 SC contains } \\
\text { bile ducts and } \\
\text { Kupffer cells }\end{array}$ \\
\hline $\begin{array}{l}\text { Hepatic } \\
\text { Adenoma }\end{array}$ & $\begin{array}{l}\text { Non-specific } \\
\text { Hyperechoic } \\
\text { Increased blood flow } \\
\text { on duplex scanning }\end{array}$ & $\begin{array}{l}\text { Non-specific } \\
\text { Non-contrast: hypo to isodense } \\
\text { Contrast: isodense with } \\
\text { peripheral enhancement with } \\
\text { subsequent centripetal flow }\end{array}$ & $\begin{array}{l}\text { Non-specific } \\
\text { Iso- hpointense T1 \& T2 } \\
\text { Uniform enhancement } \\
\text { after gadolinium }\end{array}$ & Not indicated & $\begin{array}{l}\text { Generally does } \\
\text { not take Tc99 SC } \\
\text { because of the } \\
\text { lack of bile ducts } \\
\text { and Kupffer cells }\end{array}$ \\
\hline
\end{tabular}

US = ultrasonography; $\mathrm{CT}=$ computed tomography; $\mathrm{MRI}=$ magnetic resonance imaging; $\mathrm{T} 1=\mathrm{T} 1$ - weighted $\mathrm{MRI} ; \mathrm{T} 2=\mathrm{T} 2-$ weighted MRI; Tc-99m RBC = technetium-99m-labeled red blood cell; Tc-99m SC = technetium-99m sulfur colloid.

Table 3. Radiographic appearance of benign liver neoplasms ${ }^{1,9}$

Accurate diagnosis is essential to the appropriate management of hepatic neoplasms. Although patients may require surgical intervention for diagnostic purposes, few benign tumors require surgical management for symptomatic relief. As such, surgical intervention for benign tumors is primarily indicated (1) for definitive diagnosis when imaging is inconclusive, (2) to prevent malignant transformation, such as in the case of hepatic adenoma, (3) to reduce the risk of rupture and, (4) for the treatment of rare life-threatening complications as a result of rupture or haemorrhage [9].

\section{Hemangioma}

Hemangioma is the most common benign mesenchymal neoplasm of the liver and occurs in two variants, capillary and cavernous. Hepatic hemangiomas are identified in $0.4 \%$ to $20 \%$ of all imaging studies preformed [10-14]. Hemangiomas are frequently discovered incidentally 
on autopsy studies with $60 \%-80 \%$ identified in individuals in their $4^{\text {th }}$ - $6^{\text {th }}$ decade of life [12-16].The precise etiology of hemangiomas is poorly understood but they are generally considered to be benign congenital hamartomas composed of disorganized venous vasculature separated by intervening fibrous tissue [17]. Hemangiomas vary greatly in size from a few millimeters to over $50 \mathrm{~cm}$, with the majority (up to $80 \%$ ) less than $4 \mathrm{~cm}[1,12,18]$. Although most commonly solitary, up to $40 \%$ of patients with hemangiomas have multiple tumors [19].

Capillary hemangiomas are more prevalent than are cavernous hemangiomas [1,20]. However, these hypervascular lesions are typically small $(2 \mathrm{~cm})$ and are rarely clinically significant [1]. As such, the management of capillary hemangiomas requires the exclusion of malignancy and patient reassurance that routine surveillance is not necessary in the absence of symptoms [9].

Cavernous hemangiomas are far more often clinically relevant than capillary hemangiomas. The incidence of cavernous hemangiomas is 3 times greater among women than men, with a mean age of 45 years $[12,16]$. Whether this reflects a true increase in incidence or a result of more frequent imaging amongst females remains unclear as evident by one autopsy series in which there was a nearly equal sex incidence $[1,21]$. Although no link between oral contraceptive pill (OCP) use and hemangioma incidence has been established, early studies suggest a link between OCP use and increased hemangioma size at initial presentation [18].

\section{Clinical presentation}

The most frequently reported symptoms of liver hemangiomas include abdominal pain, nausea, vomiting, early satiety, and prolonged fever [1,22]. Most symptoms of hepatic hemangioma are attributable to rapid expansion, thrombosis, or infarction, resulting in inflammation or stretching of Glisson's capsule [1]. Large hemangiomas $(>10 \mathrm{~cm})$ may occasionally present as a non-tender palpable mass in the right upper quadrant, however physical exam more often reveals only vague abdominal tenderness without a mass $[1,23]$. Occasionally, a bruit maybe detected over the liver. Evidence of intratumoral or intraperitoneal rupture may be reflected by hemoperitoneum and subsequent shock, which requires emergent surgical intervention. Rarely biliary colic, obstructive jaundice, gastric obstruction, torsion of a pedunculated lesion, pulmonary embolism, spontaneous intraperitoneal hemorrhage, and consumptive coagulopathy have been reported [22,24,25]. Kasabach-Merritt syndrome, which was originally used to describe thrombocytopenia and afibrinogenemia associated with hemangiomas on the skin and spleen of infants, is frequently used to define hepatic hemangioma patients with severe thrombocytopenia and concomitant consumptive coagulopathy [26].

\section{Pathology}

Hemangiomas are typically well demarcated from surrounding hepatic tissue, which often permits surgical enucleation [27]. In tumors not well demarcated, the tumor-parenchymal interface defines the ease with which enucleation versus formal resection is required. Four 
interface variants between the hemangioma and hepatic parenchyma have been described. The "fibrolamellar" interface is characterized by a capsule-like fibrous ring of various thickness and is the most common [9]. The involved veins parallel the periphery of the hemangioma or traverse the fibrous lamella. The healthy hepatic parenchyma is often atrophic and a plane between the hemangioma and uninvolved liver tissue is well defined. A second variant, the "compression" interface consists of a hemangioma in which the periphery of the neoplasm is well demarcated despite the absence of a fibrous lamella [1]. An "interdigiting" pattern lacks a fibrous lamella and instead is replaced by an ill-defined plane between the vascular channels of the hemangioma and uninvolved hepatic parenchyma [1]. Finally, an "irregular" or "spongy" interface occur when the hemangioma appears to intercalate into the surrounding hepatic parenchyma [1]. Despite the invasive appearance of this variant, hemangiomas do not possess any malignant potential.

The diagnosis of cavernous hemangioma is generally easy to establish with modern imaging techniques. However, in some instances atypical hemangiomas may be confused for other pathology, including but not limited to, hemorrhagic telangiectasia (Osler-Rendu-Weber), hemangioendothelioma, and peliosis hepatis [9]. When diagnosis remains unclear, indeterminate lesions should be managed surgically as percutaneous biopsy may result in uncontrollable hemorrhage [1].

\section{Radiographic evaluation}

Accurate radiographic diagnosis of hepatic hemangioma is essential since once definitive diagnosis is established no additional intervention is typically required [9]. Radiographic evaluation is largely dictated by clinical presentation as most hemangiomas are discovered incidentally on imaging studies completed for unrelated symptomology and/or pathology. Depending on the initial degree of diagnostic certainty additional imaging maybe superfluous.

B-mode ultrasonography is typically the initial imaging study performed [1]. On US hemangiomas appear as a homogenous hyperechoic mass that is well demarcated from surrounding liver parenchyma $[1,28,29]$. The addition of duplex US provides additional information regarding peripheral blood flow and central pooling of venous blood [1,28]. As malignant lesions may demonstrate similar acoustic patterns, additional imaging modalities are often required for definitive confirmation. On contrast enhanced compute tomography (CE-CT) hemangiomas initially appear as hypodense masses with a pattern of irregular peripheral nodular enhancement following initial injection of contrast [30,31]. Delayed venous images subsequently demonstrate characteristic central venous filling of the hypodense mass [30,31]. Magnetic resonance imagining (MRI), though rarely needed for diagnosis of most hemangiomas, is the most sensitive and specific modality for the detection and diagnosis of hemangioma [6,32]. T-1 weighted images reveal a smooth well-demarcated homogenous isodense mass, whereas T-2 weighted studies demonstrate a hyperdense pattern [33,34]. The administration of intravenous gadolinium diethylenetriaminepentaacetic acid (Gd-DTPA) contrast results in the pathognomonic pattern of peripheral nodular enhancement with central filling on delayed 
images $[1,35,36]$. This enhancement pattern is typical of most hemangiomas $>2 \mathrm{~cm}$ [37]. Hemangiomas $<2 \mathrm{~cm}$ may demonstrate rapid uniform enhancement which is indistinguishable from hypervascular hepatocellular carcinoma (HCC) [37]. ${ }^{18} \mathrm{~F}$-FDG PET scan may be useful for differentiation between benign and malignant hepatic tumors [38]. Studies have shown that the activity of both glucose-6-phosphatase and glucose transporters are increased in HCC resulting in decreased uptake of ${ }^{18} \mathrm{~F}-\mathrm{FDG}$ in hemangiomas as compared to HCC [8]. Historically, technetium-99 labeled red blood cells scintigram (Tc-99 RBC scan) was the gold standard for the diagnostic evaluation of hemangiomas, but technological advancements in axial imaging has led to a decline in the reliance on RBC scintigraphy [31,39]. Finally, selective hepatic angiography typically yields a characteristic neovascular "corkscrewing" appearance with rapid central filling from the neovascular periphery described as "cottonwool" [1]. Despite these characteristic findings, the high diagnostic yield of less invasive modalities makes arteriography rarely necessary.

\section{Diagnosis \& treatment}

The majority of hemangiomas are asymptomatic, particularly those lesions $<1.5 \mathrm{~cm}$ in size [1]. Although hemangiomas can grow to great sizes, they generally do not compromise liver function and as such liver function tests are often normal. In rare instances thrombosis or intraparenchymal hemorrhage may occur acutely affecting liver function tests. Spontaneous rupture of hepatic hemangiomas is an exceptionally rare event with a review of the literature revealing less than 30 cases of spontaneous rupture since 1898. Given the low yet significant risk of bleeding, fine needle aspiration (FNA) should be avoided [1]. As a rule, biopsy is only indicated if a histologic diagnosis is unclear or will alter planned treatment, thus in the absence of clinical symptoms the most appropriate treatment strategy is careful observation [1].

Surgical resection should be considered in patients with disabling pressure or pain suggestive of extrinsic compression of adjacent structures, in those experiencing acute symptoms related to rupture, or when malignancy cannot be ruled out $[22,40]$. In general clinical symptoms increase concurrently with tumor size, with most symptomatic tumors having a mean size of $10 \pm 8 \mathrm{~cm}$ as compared with $6.8 \pm 5.8 \mathrm{~cm}$ for asymptomatic lesions [41].

Surgical intervention should be approached no differently than for treatment of other hepatic tumors. It is essential that surgeons possess an extensive knowledge of the anatomy and vascular supply of the liver. The extent of hepatic resection required is directly related to the anatomic location of the lesion and its proximity to surrounding vasculature. Thus, the location of the lesion will largely dictate the operative approach hence a full evaluation of the tumor's extent is critical. Large central lesions which border the inferior vena cava, hepatic outflow tract, or the portal vein, may pose an exorbitant surgical risk and as such may not allow for resection [1].

While enucleation is often indicated, formal resection is required in certain instances. Recall it is the histological features of the tumor-parenchymal interface which defines how easily a parenchymal-sparing technique may be utilized. Unlike malignant lesions, resection of 
hemangiomas does not necessitate removal of a margin of normal tissue with the tumor. Enucleation is carried out by careful dissection within the proper plane between the hepatic parenchyma and tumor. Division and ligation of the principal hepatic artery should be completed early in the operation as this often results in significant tumor decompression thereby facilitating resection [1]. The majority of hemangiomas are contained within a tough fibrous capsule which can be clamped and used for retraction purposes [1]. As hepatic venous branches are encountered extending from the lesion they should be controlled with clips or ties [1]. Presently, mortality outcomes for resection and enucleation are comparable [42].

Hepatic artery ligation for treatment of hemangioma has also been described anecdotally [9]. Although its benefits are likely transient, hepatic artery embolization and/or ligation play a pivotal role only in the temporary management of uncontrolled hemorrhage from rupture $[43,44]$. Finally, radiation therapy for symptomatic hemangiomas has also been reported. Though data validating the use of radiotherapy is limited, it seems a reasonable approach for symptomatic hemangioma where surgical intervention is clearly contraindicated.

\section{Special issue: Hemangioma in children}

Hepatic hemangiomas of infancy and childhood differ substantially in their appearance, presentation, and progression than those in adults [1]. These lesions are frequently large and symptomatic. In contrast to adult hemangiomas, the risk of spontaneous rupture in infancy is greater [1]. Similarly, Kasabach-Merritt syndrome occurs more frequently and results more often in death among affected infants. As a result of the numerous venous lakes within these lesions, which serve as siphons for a large proportion of the total cardiac output, severe congestive heart failure and death may result. Initial treatment of high output cardiac failure in children includes oxygen, diuretics, digitalis, corticosteroids, hepatic artery ligation, and radiation therapy [2, 45-48]. Contrary to the conservative management of adult hemangiomas, hemangiomas of infancy and childhood more frequently require life-saving surgical intervention.

\section{Focal nodular hyperplasia}

Focal nodular hyperplasia (FNH) is the second most common benign hepatic lesion [20]. FNH is found predominately in women (in a ratio of 8-9:1) between the ages of 20-50 years, and has a prevalence of $4-8 \%$ in the general population [49,50]. Similar to hemangiomas, the prevalence of FNH has markedly increased over the past several decades, which likely reflects the proficiency and widespread use of advanced imaging modalities [1].

Although Klatskin (1977) and Vana (1979) each reported an association between OCP use and the development of FNH, the high frequency of FNH in the absence of OCP use suggests no causal relationship [32,51]. However, enlargement of FNH lesions has been described in the setting of pregnancy and long-term OCP use [52]. While the etiology of these lesions has not 
yet been clearly delineated, it has been suggested that FNH is a hyperplastic polyclonal response of normal hepatic parenchyma to localized areas of increased arterial perfusion [53]. Expectantly, FNH has been found in association with vascular disorders and malformations including hereditary hemorrhagic telangiectasia, hemihypertrophy Klippel-TrenaunayWeber syndrome, and congenital absence of the portal vein [49,54-57].

While typically small $(<5 \mathrm{~cm}), \mathrm{FNH}$ lesions have been reported as large as $19 \mathrm{~cm}[48,50]$. The majority of FNH lesions are solitary in nature (80\%-95\%), although up to $20 \%$ of individuals are reported to have multiple lesions [1, 48, 50]. When multifocal, FNH often occurs in conjuncture with other benign hepatic lesions including hemangiomas [58].

\section{Clinical presentation}

FNH is frequently asymptomatic with up to $75 \%$ of lesions discovered incidentally during radiologic workup, laparotomy, or laparoscopy for unrelated pathology [59]. Similar to hepatic hemangiomas, spontaneous rupture is extremely rare as illustrated by Chamberlain et. al (2003) management of 33 patients with FNH where no ruptures were evident [9]. Large, peripheral, pedunculated lesions may result in a palpable mass associated with abdominal pain and/or fullness, but acute symptoms associated with rupture, necrosis, or infarction are a rarity.

\section{Pathology}

Macroscopically FNH is a firm pale to red colored lesion with sharp margins. Lesions are typically small, pedunculated, and peripherally located. Unlike hemangiomas and hepatic adenomas, FNH lack a capsule. Histologically FNH appears as regenerative nodules making histopathological differentiation from cirrhosis difficult. Lesions contain normal hepatic elements with a haphazard arrangement of cords and sinusoids [5]. Proliferating bile ducts, fibrous septae, Kupffer cells, and sinusoids are typically present in FNH, and are characteristically absent in hepatocellular adenomas [13,50,59]. Generally FNH contain a large artery with multiple branches radiating through disorganized fibrous septa to the periphery. This radiating arterial pattern produces a spoke and wheel image on angiography and is responsible for the central scar appearance on radiographic imaging studies [60,61].

\section{Radiographic imaging}

Definitive diagnosis of FNH can be challenging. FNH lesions are well visualized on US but are highly variable and exhibit no distinct characteristic features. Helical CE-CT reveals a welldemarcated lesion that is often isodense [29]. However, during the portal venous phase the pathognomonic central scar may be appreciated. Distinguishing FNH on standard MRI can 
prove challenging as the lesion is composed of the similar elements as the normal liver parenchyma. FNH may appear isointense with a central scar on T-1 and T-2 weighted imaging [62]. MRI with Gd-DTPA demonstrates a hyperintense lesion early, which becomes isointense with central scar enhancement on delayed imaging [63-65]. The use of reticuloendothelial agents including Ferridex, which is taken up selectively by Kupffer cells, increases the specificity of both CT and MRI imaging [1]. Technetium-99-labeled sulfur colloid scintigraphy may prove helpful in demonstrating the presence of Kupffer cells within the FNH lesion, however this finding is not specific enough for definitive diagnosis [1,66,67]. Angiography, though rarely indicated for the diagnosis of $\mathrm{FNH}$, usually demonstrates a hypervascular mass with a single central artery and enlarged peripheral vessels in a "spoken wheel" appearance [66-68]. Finally, ${ }^{18}$ F-FDG PET can aid in the differentiation between benign and malignant lesions, but it is neither sensitive nor specific enough for diagnosis of $\mathrm{FNH}[8,38]$.

\section{Diagnosis \& treatment}

The natural course of an FNH lesion is generally indolent with minimal risk of rupture or complication. Laboratory testing generally reveals normal liver function tests and alpha-fetoprotein levels, although minor elevations in aspartate and alanine aminotransferase, alkaline phosphatase, and gamma glutamyl transpeptidase may occasionally be seen. Definitive diagnosis of $\mathrm{FNH}$ in an asymptomatic patient warrants conservative management and includes close observation with repeat imaging every four to six months [9]. When radiology is equivocal, most surgeons still choose close observation with follow-up studies preformed every three to four months. Biopsy is generally not indicated, as results are seldom diagnostic [69].

Although it may be impossible to distinguish FNH from a well-differentiated HCC without surgical excision, FNH tumors do not undergo malignant transformation. Thus indications for surgical intervention should be limited to those situations where there is a change in the size or number of lesion(s), a change in the intensity of symptoms, or where classic imaging characteristics are absent and diagnostic dilemma remains [70]. Hence, the role of the surgeon is typically limited to patient reassurance and close observation [9].

\section{Hepatic adenoma}

Hepatic adenomas are identified predominately in women of reproductive age [49]. The estimated prevalence of hepatic adenomas within the general population on postmortem exams is approximately 1\% [10]. Etiologically, hepatic adenomas are of epithelial origin. Unlike hepatic hemangiomas and $\mathrm{FNH}$, a clear association between the use of OCPs and hepatic adenomas has been established. First described in 1973, multiple studies have documented a reciprocal relationship between OCP use and adenoma incidence based on estrogen dose and exposure time [71-75]. Approximately $90 \%$ of individuals with adenomas have previous OCP 
exposure [1]. The prevalence of hepatic adenomas is estimated at 1 per 1,000,000 among women who have never used OCP as compared with 30-40 per 1,000,000 amongst long-term OCP users $[72,76]$. OCPs also affect the course of disease progression as lesions are generally larger, more numerous, and more likely to bleed than tumors in OCP-naïve individuals $[32,75,77,78]$. Adenoma regression has been observed in patients after discontinuation of OCP with recurrence ensuing during pregnancy and/or OCP re-administration [72,79,-82]. Despite these findings, the mechanism by which estrogen therapy affects the development and course of hepatic adenomas has yet to be clearly elucidated.

Hepatic adenomas are typically small $(<5 \mathrm{~cm})$, soft, solitary lesions but may be multiple in up to $30 \%$ of cases [9]. Of note, hepatic adenomatosis disease, defined as the presence of $>10$ lesions, is a distinct disease entity from that of hepatic adenoma and as such will not be described in further detail [83]. Hepatic adenomas have been associated with type I glycogen storage disease, galactosemia, Klienfelter's syndrome, and Turner's syndrome as well as with androgen, domiphene, danazol and growth hormone use [1,84-86]. Although hepatic adenomas are benign, these lesions have been associated with spontaneous hemorrhage, rupture, and malignant transformation, making prognosis more grave than that of other benign hepatic tumors [5,87].

\section{Clinical presentation}

Since adenoma and FNH both present in women of reproductive age and have similar radiographic appearances they are frequently confused. Differential diagnosis is critical given that the recommended treatment of each respective lesions differs. Hepatic adenomas are most often diagnosed as a result of imaging done for unrelated pathology or following workup of a palpable abdominal mass (30\% patients) [88]. Occasionally episodic pain may be evident as a result of an enlarged liver, intratumoral bleed, or tumor necrosis [9]. Up to $33 \%$ of patients with hepatic adenomas present with acute rupture and concomitant intraperitoneal bleeding [1]. The development of acute severe pain associated with hypotension reflects spontaneous rupture and carries a $20 \%$ mortality rate if not appropriately identified and treated [32,89-91].

\section{Pathology}

Grossly hepatic adenomas appear as smooth, soft, and pale yellow tumor on cut surface [1]. These lesions often contain prominent blood vessels that have a high potential for rupture and hemorrhage [1]. As adenomas lack a fibrous capsule intraparenchymal bleeding may occur, which frequently results in a variegated appearance.

Microscopically hepatic adenomas appear as well circumscribed lesions composed of monotonous sheets of hepatocytes laden with glycogen and lipids [5]. These lesions lack normal hepatic architecture and demonstrate thickened trabeculae interspersed with sinusoids and 
prominent thin walled vessels [1,5]. Biliary ducts and portal tracts are distinctly absent from adenomas.

While the malignant potential of adenomas remains controversial, several authors have reported a low (5\%) yet consistent risk of transformation [87]. Histological differentiation between well differentiated HCC and adenoma can be difficult, especially in the presence of fibrolamellar HCC which is also more common in women of reproductive age. This issue is further explained in situations in which HCC and hepatic adenoma have been found adjacent to one another $[61,50,89,92,93]$.

\section{Radiological imaging}

Although radiographic evaluation is important for complete workup of hepatic adenoma radiographic features are often nonspecific [94]. As such, despite the use of multiple imaging techniques, diagnosis often remains equivocal. Ultrasound exhibits a mixed echogenic pattern with an overall heterogeneous appearance [1,29]. Lesions appear hyperechoic as a result of their high lipid content with a heterogeneous pattern reflecting intratumoral hemorrhage and necrosis [95]. CE-CT imaging is frequently utilized for adenoma visualization and typically demonstrates a hypo- to isodense lesion as a result of low attenuation on non-contrast phase [1]. A variegated appearance with peripheral enhancement during the early contrast phase with subsequent centripetal flow during the venous phase may be apparent, however CT can demonstrate a spectrum of disparate findings [96]. MRI findings for hepatic adenoma are similar to those on CT. Due to the high fat and glycogen content, adenomas are usually well demarcated on MRI imaging [29]. While most adenomas appear iso- to hyperintense on both T-1 and T-2 weighted images, findings are highly variable [1,97]. The administration of contrast agents including gadolinium or gabodenate dimeglumine (Gd-BOPTA) results in early markedly uniform enhancement on arterial phase, which subsequently becomes isodense on the portal venous phase [98]. The use of ${ }^{18}$ FDG PET scan may also aid in the differentiation of benign versus malignant disease in which where adenomas demonstrate poor uptake of ${ }^{18} \mathrm{FDG}$ as compared to HCC $[8,38]$.

Additional imaging modalities infrequently used include technetium-99 sulfur colloid scanning. This imaging modality is particularly useful in differentiating between hepatic adenoma and FNH, as hepatic adenomas lack bile duct components and frequently appear as a "cold nodules" on imaging [99]. Occasionally however, a minority of lesions do take up the sulfur colloid, rendering them indistinguishable from FNH [99]. Although rarely utilized, angiography typically reveals hypervascular lesions with areas of hemorrhage and necrosis $[1,28]$.

\section{Diagnosis \& treatment}

In the absence of acute hemorrhage, serological tests rarely assist in diagnosis. Liver function tests and tumor makers including CEA, alpha-fetoprotein, and CA 19-9 are invariably normal. 
Hepatic adenomas pose a greater risk for rupture (33\%) and malignant transformation (5\%) than do other benign hepatic lesions $[9,87]$. As such all patients with suspected or confirmed hepatic adenoma $>3 \mathrm{~cm}$ should undergo enucleation or surgical resection $[1,100]$. The approach to surgical excision should be as previously described. Since all adenomas are suspected to harbor malignancy an adequate margin of normal parenchyma should be taken [1]. When surgical exploration is not feasible angiographic embolization or ligation can provide temporary yet life saving relief.

As a result of the relationship between OCP and adenoma incidence, it is recommended that all individuals suspected of having an adenoma discontinue the use of OCP immediately and indefinitely [1,61]. Patients should also be advised against pregnancy until after adenoma resection, as the growth and rupture risk of hepatic adenomas is highly unpredictable during gestation [101]. Yearly follow-up with imaging is advised among all patients where a causal link between OCP use and adenoma is absent [9]. As a result of improved safety of hepatic resection and the use of minimally invasive techniques in hepatectomy it is suggested that all hepatic adenomas $>3 \mathrm{~cm}$ be resected $[1,100]$. In patients with significant contraindications to surgical intervention, OCP should be discontinued and the patient enrolled in an ongoing surveillance program [9].

\section{Additional liver tumors}

\subsection{Epithelial tumor}

\section{Biliary hamartomas}

Bile duct adenomas and hamartomas are common tumors. Bile duct adenomas appear as small, white, solitary, subcapsular masses [1]. They are defined histologically by narrow lumen bile ducts surrounded by fibrosis. Hamartomas appear as small gray-white nodules that lie just beneath the capsule of the liver [102]. Biliary hamartomas are frequently multifocal and are characterized microscopically by the presence of dilated mature bile ducts surrounded by fibrous tissue [1]. These lesions are especially important as they are frequently misinterpreted as metastatic tumor by the operating surgeon. This notion heightens the importance of confirmatory diagnosis to rule out malignancy for all hepatic lesions. Precise diagnosis is most important in situations in which the presence of a metastatic liver disease will alter the proceedings of a planned operation.

\subsection{Mesenchymal tumors}

Solitary fibrous tumor (other names include benign mesothelioma or fibroma)

Solitary fibrous tumors (SFT) are rare mesenchymal tumors that are frequently mistaken for metastatic lesions as a result of their radiographic and intra-operative appearance. Grossly SFT's appear as white-to-gray lesions and can vary greatly in size ranging from $2-20 \mathrm{~cm}$ in diameter [1]. Despite their large size, most SFT's remain asymptomatic. Histologically, most have a classic short storiform pattern and display an absence of cellular atypia, mitoses, 
and/or necrosis [1]. However when malignant, SFTs frequently possess a high mitotic rate and marked cellular atypia. Immunohistochemically SFTs display a strong positive staining for vimentin and CD-34 [1]. Since definitive histologic examination is required for diagnosis of either a benign or malignant SFT, surgical resection is indicated in nearly all circumstances.

\section{Lipoma, myelolipoma, or angiomyelipoma}

Similar to several other benign hepatic lesions, most benign fatty hepatic tumors are identified at the time of autopsy with only isolated reports of histological diagnosis following operative resection [13]. Multiple variants including angiolipoma, myelolipoma, and angiomyolipoma have been described [13,103]. Additionally, "pseudolipomas" have been described as lesions in which there is an extracapsular fatty tumor with involutional changes. It is probable that this lesion results when a free-floating piece of fat becomes entrapped between diaphragm and liver surface [1,10]. In most situations definitive diagnosis requires surgical resection to exclude malignancy.

\section{Mesenchymal Hamartomas}

Mesenchymal hamartomas are exceedingly rare congenital liver tumors which occur most frequently in infants under 1 year of age $[9,104]$. Microscopically these lesions demonstrate a myxoid background of highly cellular embryonal mesenchyme with haphazard groupings of bile ducts, cysts, and hepatic cells [105]. Generally, the cystic element is the most prominent feature resulting in a characteristic "honeycomb" appearance [106]. In contrast to biliary hamartomas, which are clinically insignificant, mesenchymal hamartomas can significantly impair hepatic function as a result of their large size [106]. Although benign, these lesions can result in death due to mass effect and/or hepatic insufficiency [1]. Thus, all suspected mesenchymal hamartomas should be completely excised when possible. If complete surgical excision cannot be achieved surgical debulking may be sufficient as there have been no reports of recurrence after an incomplete surgical resection to date [107].

\section{Myxoma}

Myxomas are exceptionally uncommon benign lesions of the liver. To date fewer than five cases have been reported $[9,58,108]$. These lesions arise from primitive connective tissue. Histologically myxomas demonstrate a myxoid matrix with scattered proliferation of connective tissue cells [108]. Similar to other types of hepatic tumors described above, surgical resection is generally indicated to exclude malignancy.

\section{Teratoma}

Primary teratomas are remarkably rare benign hepatic lesions. A review of the literature revealed only 7 reports to date, with the majority of lesions occurring in children [109]. Secondary hepatic teratomas have been observed following systemic chemotherapy administration for treatment of testicular cancer [1]. Teratomas arise from pluripotent cells and frequently contain components from all three germ layers. Teratomas are typically encapsulated cystic lesions that are easily resectable [1,110]. Imaging characteristics reflect tissue heterogeneity and are often non-specific [110]. Surgical resection of hepatic teratomas is indicated to exclude malignancy. 


\section{Conclusion}

A thorough understanding of the natural history and accurate histologic diagnosis are fundamental to appropriate management of patients with benign liver tumors. Although advancements in imaging have drastically improved the detection and characterization of both benign and malignant liver neoplasms, the ultimate burden of responsibility for diagnosis and treatment remains that of the surgeon. Ongoing improvements in perioperative care and surgical techniques, coupled with increased surgical experience presently permit hepatic resection to be performed with a high level of safety. Despite these developments, a conservative approach including close observation with serial examination and imaging seems most appropriate for asymptomatic patients in which malignancy is not suspected.

Symptomatic patients without medical or anatomic contraindication to a major hepatic resection, as well as patients in whom a malignancy cannot be excluded (including individuals with adenomas $>3 \mathrm{~cm}$ ), should be considered for surgical intervention. Preoperative needle biopsy is frequently contraindicated due to a high risk of rupture and hemorrhage, and therefore should only be considered after exclusion of hemangioma. Additionally, it is important to note that distinguishing particular lesions (especially adenoma and $\mathrm{FNH}$ ) on needle biopsy is exceedingly difficult. As such caution should exercised when using this information to make clinical evaluations. Excisional biopsy of small and peripheral lesions and adequate wedge incision biopsy of large lesions should permit the pathologist to make an accurate histologic diagnosis and exclude a malignancy. If doubt remains, formal hepatic resection is indicated.

\section{Author details}

Ronald S. Chamberlain ${ }^{1,2,3}$ and Kim Oelhafen ${ }^{3}$

1 Department of Surgery, Saint Barnabas Medical Center, Livingston, NJ, USA

2 Department of Surgery, University of Medicine and Dentistry of New Jersey, Newark, NJ, USA

3 Saint George's University School of Medicine, Grenada, West Indies, Grenada

\section{References}

[1] Chamberlain RS, DeCorato D, Jarnagin W. Benign liver lesions. In Blumgart L, Fong Y, \& Jarnagin W. (ed.) American Cancer Society Atlas of Clinical Oncology Hepatobiliary Cancer. British Colombia: Decker Inc; 2001. p1-30. 
[2] Little JM, Kenny J, Hollands MJ. Hepatic incidentaloma: a modern problem. World J Surg 1990;14(4): 448-51.

[3] Little JM, Richardson A, Tait N. Hepatic dyschoma: a five-year experience. HPB Surg 1991;4(4): 291-8.

[4] Izzo F, Cremona F, Ruffolo F, Palaia R, Parisi V, Curley SA. Outcome of 67 patients with hepatocellular cancer detected during screening of 1125 patients with chronic hepatitis. Ann Surg 1998;227(4): 513-8.

[5] Sonnenday C, Welling T, Pelletier S. Hepatic Neoplasms. In Mulholland M \& Lillemoe $K$, et al ( $5^{\text {th }}$ ed.) Greenfield's Surgery: Scientific Principles \& Practice. Philadelphia: Wolter Kluwer/Lippincott Williams \& Wilkins; 2011. p934-94.

[6] Yoon SS, Charny CK, Fong Y, Jarnagun WR, Schwartz LH, Blumgart LH et al. Diagnosis, management, and outcomes of 115 patients with hepatic hemangioma. J Am Coll Surg 2003;197(3): 392-402.

[7] Balci NC, Befeler AS, Leiva P, Pilgram TK, Havlioglu N. Imaging of liver disease: comparison between quadruple-phase multidetector computed tomography and magnetic resonance imaging. J Gastroenterol Hepatol 2008;23(10): 1520-7.

[8] Sacks A, Peller P, Surasi D, Chatburn L, Mercier G, Subramaniam RM. Value of PET/CT in the Management of Primary Hepatobiliary Tumors, Part 2. AJR Am J Roentgenol 2011;197(2): W260-5.

[9] Chamberlain RS. Benign Tumors of the Liver: a surgical perspective. In Chamberlain RS \& Blumgart LH (ed.) Hepatobiliary Surgery. Texas: Landes Bioscience; 2003. p81-99.

[10] Karhunen PJ. Benign hepatic tumours and tumour like conditions in men. J Clin Pathol 1986;39(2): 183-88.

[11] Lam KY. Autopsy findings in diabetic patients: a 27-yr clinicopathologic study with emphasis on opportunistic infections and cancers. Endocr Pathol 2002;13(1): 39-45.

[12] Gandolfi L, Leo P, Solmi L, Vitelli E, Verros G, Colecchia A. Natural history of hepatic hemangiomas: clinical and ultrasound study. Gut 1991;32(6): 677-80.

[13] Ishak KG, Rabin L. Benign tumors of the lover. Med Clin North Am 1975;59(4): 995-1013.

[14] Gilon D, Slater PE, Benbassat J. Can decisions analysis help in the management of giant hemangioma of the liver? J Clin Gastroenterol 1991;13(3): 255-8.

[15] Edmondson HA. Tumors of the liver and intrahepatic bile duct. In: Atlas of tumor pathology. Section VII, fascicle 25. Washington DC: Armed Forces Institute of Pathology; 1958.

[16] Farges O, Daradkeh S, Bismuth H. Cavernous hemangioma of the liver: are there any indications for resection? World J Surg 1995;19(1): 19-24. 
[17] Sewell JH, Weiss K. Spontaneous rupture of hemangioma of the liver. A review of the literature and presentation of illustrative case. Arch Surg 1961;83: 729-33.

[18] Glinkova V, Shevah O, Boaz M, Levine A, Shirin H. Hepatic haemangiomas: possible association with female sex hormones. Gut 2004;53(9): 1352-5.

[19] Little JM. Benign tumors of the liver. In: Terblanche J (ed). Hepatobiliary malignancies: its multidisciplinary management. London: Edward Arnold; 1994. p325-49.

[20] Tait N, Richardson AJ, Muguti G, Little JM. Hepatic cavernous hemangioma: a 10-year review. Aust N Z J Surg 1992;62(7): 521-4.

[21] Dockerty MB, Gray HK, Henson SW. Benign tumors of the liver. II. Hemangiomas. Surg Gynecol Obstet 1965;103(3): 327-31.

[22] Shumacker HB. Hemangioma of the liver: discussion of symptomatology and report of patient treated by operation. Surgery 1942;11: 209-22.

[23] Griecco MB, Miscall BG. Giant hemangioma of the liver. Surg Gyncecol Obstet 1978;147(5): 783-7.

[24] Ochsner JL, Halpert B. Cavernous hemangioma of the liver. Surgery 1958;43(4): 577-82.

[25] Dennis M. Fatal pulmonary embolism due to thrombosis of a hepatic cavernous hemangioma. Med Law 1980;20(4): 287-8.

[26] Hall GW. Kasabach-Merritt syndrome: pathogenesis and management. Br J Haematol 2001;112(4): 851-62.

[27] Baer HU, Dennsion AR, Mouton W, Stain SC, Zimmermann A, Blumgart LH. Enucleation of giant hemangiomas of the liver. Technical and pathologic aspects of a neglected procedure. Ann Surg 1992;216(6): 673-6.

[28] Assy N, Nasser G, Djibre A, Beniashvilli Z, Zidan J. Characteristics of common solid liver lesions and recommendations for diagnostic workup. World J Gastroenterol 2009;15(26): 3217-27.

[29] Madrazo BL. Use of imaging studies to aid in the diagnosis of benign liver tumors. Gastroenterol Hepatol (N Y) 2011;7(10): 683-5.

[30] Trastek VF, van Heerden JA, Sheedy PF II, Adson MA. Cavernous hemangiomas of the liver: resect of observe? Am J Surg 1983;145(1): 49-53.

[31] Foster JH. Evaluation of asymptomatic solitary hepatic lesions. Annu Rev Med 1988;39: 85-93.

[32] Klatskin G. Hepatic tumors: possible relationship to use of oral contraceptives. Gastroenterology 1977;73(2): 386-94.

[33] McFarland EG, Mayo-Smith WW, Saini S, Hahn PF, Goldberg MA, Lee MJ. Hepatic hemangiomas and malignant tumors: improved differentiation with heavily T2weighted conventional spin-echo MR imaging. Radiology 1994;193(1): 43-7. 
[34] Goshima S, Kanematsu M, Kondo H, Yokoyama R, Kajita K, Tsuge Y, et al. Hepatic hemangiomas: a multi-institutional study of appearance on T2-weighted MR findings and apparent diffusion coefficients. Eur J Radiol 2009;70(2): 325-30.

[35] Adam A, Dixon AK, Grainger RG, et al. A Textbook of Medical Imaging. $5^{\text {th }}$ ed. Philadelphia, PA: Churchill Livingston/Elsevier; 2008.

[36] Fulcher AS, Sterling RK. Hepatic neoplasms: computed tomography and magnetic resonance features. J Clin Gastroenterology 2002;34(4): 463-71.

[37] Kim T, Federle MP, Baron RL, Peterson MS, Kawamori Y. Discrimination of small hepatic hemangiomas from hypervascular malignant tumors smaller than $3 \mathrm{~cm}$ with three-phase helical CT. Radiology 2001;219(3): 699-706.

[38] Kurtaran A, Becherer A, Pfeffel F, Muller C, Traub T, Schmalijohann J, et al. 18Ffluorodeoxyglucose (FDG)-PET features of focal nodular hyperplasia (FNH) of the liver. Liver 2000;20(6): 487-90.

[39] Farlow DC, Chapman RP, Gruenewald SM, Antico VF, Farrell GC, Little JM. Investigation of focal hepatic lesions: is tomographic red blood cell imaging useful? World J Surg 1990;14(4): 463-7.

[40] Alper A, Ariogul O, Emre A, Uras A, Okten A. Treatment of liver hemangiomas by enucleation. Arch Surg 1988;123(5): 660-1.

[41] Charny CK, Jarnagin WR, Schwartz LH, Frommeyer HS, DeMatteo RP, Fong Y, et al. Benign liver tumors: radiologic and surgical management. Br J Surg 2000;88(6): 808-13.

[42] Giuliante F, Ardito F, Vellone M, Giordano M, Ranucci G, Piccoli M, et al. Reappraisal of surgical indications and approach for liver hemangioma: a single center experience on 74 patients. Am J Surg 2011;201(6): 741-8.

[43] Nishida O, Satoh N, Alam AS, Uchino J. The effect of hepatic artery ligation for irresectable cavernous hemangioma of the liver. Am Surg 1988;54(8): 483-6.

[44] DeLorimier AA, Simpson BB, Braum RS, Carlsson E. Hepatic-artery ligation for hepatic hemangiomatosis. N Engl J Med 1967;277(7): 333-7.

[45] Park WC, Phillips R. The role of radiation therapy in the management of hemangiomas of the liver. JAMA 1970;212(9): 1496-8.

[46] Dehner LP, Ishak KG. Vascular tumors of the liver in infants and children. A study of 20 cases and review of the literature. Arch Pathol 1971;92(2): 101-11.

[47] Clatworthy HW, Boles ET, Newton WA. Primary tumors of the liver in infants and children. Arch Dis Child 1960;35: 22-8.

[48] Nguyen L, Shandling B, Ein S, Stephens C. Hepatic hemangioma in childhood: medical management or surgical resection? J Pediatr Surg 1982; 17(5):576-9.

[49] Wanless IR, Mawdsley C, Adams R. On the pathogenesis of focal nodular hyperplasia of the liver. Hepatology 1985;5(6): 1194-200. 
[50] Craig J, Peters R, Edmundson H. Tumors of the liver and intrahepatic bile ducts, Fascicle 26. ( $2^{\text {nd }}$ ed.). Washington DC: DC Armed Forces Institute of Pathology; 1989. p6.

[51] Vana J, Murphy GP, Aronoff BL, Baker HW. Survey of primary liver tumors and oral contraceptive use. J Toxicol Environ Health 1979;5(2-3): 255-73.

[52] Scott LD, Katz AR, Duke JH, Cowan DF, Maklad NF. Oral contraceptives, pregnancy, and focal nodular hyperplasia of the liver. JAMA 1984;251(11): 1461-3.

[53] Poon RT, Fan ST. Assessment of hepatic reserve for indication of hepatic resection: how I do it. J Hepatobiliary Pancreat Surg 2005;12(1): 31-7.

[54] Rebouissou S, Bioulac-Sage P, Zucman-Rossi J. Molecular pathogenesis of focal nodular hyperplasia and hepatocellular adenoma. J Hepatol 2008;48(1): 163-70.

[55] Altavilla G, Guariso G. Focal nodular hyperplasia of the liver associated with portal vein agenesis: a morphological and immunohitsochemical study of one case and review of the literature. Adv Clin Path 1999;3(4): 139-45.

[56] Buscarini E, Danesino C, Plauchu H, de Fazio C, Olivieri C, Brambilla G, et al. High prevalence of hepatic focal nodular hyperplasia in subjects with hereditary hemorrhagic telangiectasia. Ultrasound Med Biol 2004;30(9): 1089-97.

[57] De Gaetano AM, Gui B, Macis G, Manfredi R, Di Stasi C. Congenital absence of the portal vein associated with focal nodular hyperplasia in the liver in a adult woman: imaging and review of the literature. Abdom Imaging 2004;29(4): 455-9.

[58] Mathieu D, Zafrani ES, Anglade MC, Dhumeaux D. Association of focal nodular hyperplasia and hepatic hemangioma. Gastroenterology 1989;97(1): 154-7.

[59] Goodman, ZD. Benign Tumors of the Liver. In: Okuda K, Ihak KD. (ed.) Neoplasms of the Liver. Tokyo: Springer; 1987. p105.

[60] Whelan Jr, Baugh JH, Chandon S. Focal nodular hyperplasia of the liver. Ann Surgery 1973;177(2): 150-8.

[61] Kerlin P, Davis GL, McGill DB, Weiland LH, Adson MA, Sheedy PF $2^{\text {nd }}$. Hepatic adenoma and focal nodular hyperplasia: clinical, pathologic and radiologic features. Gastroenterology 1983;8(5 Pt 1): 994-1002.

[62] Mattison GR, Glazer GM, Quint LE, Francis IR, Bree RL, Ensminger WD. MR imaging of hepatic focal nodular hyperplasia: characterization and distinction from primary malignant hepatic tumors. ARJ 1987;148(4): 711-5.

[63] Irie H, Honda H, Kaneko K, Kuroiwa T, Fukuya T, Yoshimitsu K, et al. MR imaging of focal nodular hyperplasia of the liver: value of contrast-enhanced dynamic study. Radiat Med 1997;15(1): 29-35. 
[64] Mahfouz AE, Hamm B, Taupitz M, Wolf KJ. Hypervascular liver lesions: differentiation of focal nodular hyperplasia from malignant tumors with dynamic gadoliniumenhanced MR imaging. Radiology 1993;186(1): 133-8.

[65] Rummeny E, Weissleder R, Sironi S, Stark DD, Comptom CC, Hahn PF, et al. Central scars in primary liver tumors: MR features, specificity, and pathologic correlation. Radiology 1989;171(2): 323-6.

[66] Mergo PJ, Ros PR. Benign Lesions of the Liver. In The Radiologic Clinics of North America $2^{\text {nd }}$ ed. Philadelphia: WB Saunders; 1998. p319.

[67] Rogers JV, Mack LA, Freeny PC, Johnson ML, Sones PJ. Hepatic focal nodular hyperplasia: angiography, CT, sonography, and scintigraphy. ARJ Am J Roentgenol 1981;137(5): 983-90.

[68] Welch TJ, Sheedy PF $2^{\text {nd }}$, Johnson CM, Stephens DH, Charboneau JW, Brown ML, et al. Focal nodular hyperplasia and hepatic adenoma: comparisons of the angiography, CT, US, and scintigraphy. Radiology 1985;156(5): 593-5.

[69] Fabre A, Audet P, Vilgrain V, Nguyen BN, Valla D, Belghiti J, et al. Histological scoring of liver biopsy in focal nodular hyperplasia with atypical presentation. Hepatology 2002;35(2): 414-20.

[70] Bonney GK, Gomez D, Al-Mukhtar A, Toogood GJ, Lodge JP, Prasad R. Indication for treatment and long-term outcome of focal nodular hyperplasia. HPB (Oxford) 2007;9(5): 368-72.

[71] Baum JK, Bookstein JJ, Holtz F, Klein EW. Possible association between benign hepatomas and oral contraceptives. Lancet 1973;2(7835): 926-9.

[72] Rooks JB, Ory HW, Ishak KG, Strauss LT, Greenspan JR, Hill AP, et al. Epidemiology of hepatocellular adenoma. The role of oral contraceptive use. JAMA 1979;242(7): 644-8.

[73] Nime F, Pickren JW, Vana J, Aronoff BL, Baker HW, Murphy GP. The histology of liver tumors in oral contraceptive users observed during a national survey by the American College of Surgeons Commission on Cancer. Cancer 1979;44(4): 1481-9.

[74] Rosenberg L. The risk of liver neoplasia in relation to combined oral contraceptive use. Contraception 1991;43(6): 643-52.

[75] Søe KL, Søe M, Gluud C. Liver pathology associated with the use of anabolic-androgenic steroids. Liver 1992;12(2): 73-9.

[76] Reddy KR, Schiff ER. Approach to a liver mass. Semin Liver Dis 1993;13(4): 423-35.

[77] Shortell CK, Schwartz SI. Hepatic adenoma and focal nodular hyperplasia. Surg Gynecol Obstet 1991;173(5): 426-31.

[78] Meissner K. Hemorrhage cause by ruptured liver cell adenoma following long term oral contraceptives: a case report. Hepatogastroenterolog 1998;45(19): 224-5. 
[79] Edmondson HA, Reynolds TB, Henderson B , et al. Regression of liver cell adenoma associated with oral contraceptives. Ann Intern Med 1977:86(2): 180-2.

[80] Kawakatsu M, Vilgrain V, Erlinger S, Nahum H. Disappearance of liver cell adenoma: CT and MR imaging. Abdom Imaging 1997;22(3): 274-6.

[81] Aseni P, Sansalone CV, Sammartino C, Benedetto FD, Carrafiello G, Giacomoni A, et al. Rapid disappearance of hepatic adenoma after contraceptive withdrawal. J Clin Gastroenterology 2001;33(3): 234-6.

[82] Norris, S. Drug- and Toxin-Induced Liver Injury. In: Comprehensive Clinical Hepatology, O'Grady, J, Lake, J, Howdle, P. (eds). London: Harcourt Publishers Limited; 2000. p1

[83] Flejou JF, Barge J, Menu Y, Degott C, Bismuth H, Potet F, et al. Liver adenomatosis. An entity distinct from liver adenoma? Gastroenterology 1985;89(5): 1132-8.

[84] Labrune P, Trioche P, Duvaltier I, Chevalier P, Odievre M. Hepatocellular adenomas in glycogen storage disease type I and III: a series of 43 patients and review of the literature. J Pediatr Gastroenterol Nutr 1997;24(3): 276-9.

[85] Espat J, Chamberlain RS, Sklar C, Blumgart LH. Hepatic adenoma associated with recombinant human growth hormone therapy in a patient with Turner's syndrome. Dig Surg 2000;17(6): 640-3.

[86] Carrasco D, Prieto J, Pallardó L, Moll JL, Cruz JM, Munoz C, et al. Multiple hepatic adenomas after long term therapy with testosterone enanthate. Review of the literature. J Hepatol 1985;1(6): 573-8.

[87] Colli A, Fraquelli M, Massironi S, Colucci A, Paggi S, Conte D. Elective surgery for benign liver tumours. Cochrane Database sys Rev 2007;24(1): CD005164.

[88] Molina E, Schiff E. Benign solid lesions of the liver. In: Schiff E, Sorrell M, Maddrey W. (eds). Schiff's Disease of the liver ${ }^{\text {th }}$ ed. Philadelphia: Lippincott-Rave; 1999. p1245.

[89] Leese T, Farges O, Bismuth H. Liver cell adenomas. A 12-year surgical experience from a specialist hepato-biliary unit. Ann Surg 1988; 208(5): 558-64.

[90] Nagorney DM. Benign hepatic tumors: focal nodular hyperplasia and hepatocellular adenoma. World J Surg 1995;19(1): 13-8.

[91] Rubin RA, Mitchell DG. Evaluation of the solid hepatic mass. Med Clin North Am 1996;80(5): 907-28.

[92] Gyorffy EJ, Bredfeldt JE, Black WC. Transformation of hepatic cell adenoma to hepatocellular carcinoma due to oral contraceptive use. Ann Intern Med 1989;110(6): 489-90.

[93] Tesluk H, Lawrie J. Hepatocellular adenoma. Arch Pathol Lab Med 1981;105(6): 296-9.

[94] Mathieu D, Bruneton JN, Drouillard J, Pointreau CC, Vasile N. Hepatic adenomas and focal nodular hyperplasia: dynamic CT study. Radiology 1986;160(1): 53-8. 
[95] Golli M, Van Nhieu JT, Mathieu D, Zafrani ES, Cherqui D, Dhumeaux D, et al. Hepatocellular adenoma: color Doppler US and pathologic correlations. Radiology 1994;190(3): 741-4.

[96] Grazoli L, Federle MP, Brancatelli G, Ichikawa T, Olivetti L, Blachar A. Hepatic adenomas: imaging and pathologic findings. Radiographics 2001;21(4): 877-92.

[97] Chung KY, Mayo-Smith WW, Saini S, Rahmouni A, Golli M, Mathieu D. Hepatocellular adenoma: MR imaging features with pathologic correlation. ARJ Am J Roentgenol 1994;163(2): 303-8.

[98] Paulson EK, McClellan JS, Washington K, Spritzer CE, Meyers WC, Baker ME. Hepatic adenoma: MR characteristics and correlation with pathological findings. AJR 1994;163(1): 113-6.

[99] Rubin RA, Lichenstein GR. Hepatic scintigraphy in the evaluation of solitary solid liver masses. J Nucl Med 1993;34(4): 697-705.

[100] Koffron A, Geller D, Gamblin TC, Abecassis M. Laparoscopic liver surgery; Shifting the management of liver tumors. J Hepatology 2006;44(6):1694-700.

[101] Bis KA, Waxman B. Rupture of the liver associated with pregnancy: a review of the literature and report of 2 cases. Obstet Gynecol Surv 1976;31(11); 763-73.

[102] Moran CA, Ishak KG, Goodman ZD. Solitary fibrous tumor of the liver: a clinicopathologic and immunohistochemical study of nine cases. Ann Diagn Pathol 1998;2(1): 19-24.

[103] Pounder DJ. Hepatic angiomyolipoma. Am J Surg Pathol 1982;6(7): 677-81.

[104] Grases PJ, Matos-Villaobos M, Arcia-Romero F, Lecuna-Torres V. Mesenchymal hamartoma of the liver. Gastroenterology 1979;76(6): 1466-9.

[105] Stocker JT, Ishak KG. Mesenchymal hamartoma of the liver: report of 30 cases and review of the literature. Pediatr Pathol 1983;1(3): 245-67.

[106] Klaassen Z, Paragi PR, Chamberlain RS. Adult Mesenchymal hamartoma of the liver: Case report. Case Rep Gastroenterol 2010;4(1):84-92.

[107] Foster JH, Berman M. Solid Liver Tumors. Philadelphia, PA: WB Saunders; 1977.

[108] Yoon GS, Kang GH, Kim OJ. Primary myxoid leiomyoma of the liver. Arch Pathol Lab Med 1998;122(12): 1112-5.

[109] Ukiyama E, Endo M, Yoshida F. Hepatoduodenal ligament teratoma with hepatic artery running inside. Pediatr Surg Int. 2008;24(11): 1239-42.

[110] Prasad SR, Wang H, Rosas H, Menias CO, Narra VR, Middleton WD, et al. Fatcontaining lesions of the liver: radiologic-pathologic correlation. Radiographics 2005;25(2): 321-31. 
